\title{
Effective Maintenance of Gas Turbine Power Plant to Improve Productivity
}

\author{
Daniel Humphrey, Barinyima Nkoi and Isaac Okwu E.
}

\begin{abstract}
This research work identified strategies to effectively maintain the gas turbine power plant as to improve on productivity. The main aim is to determine the effect of a good maintenance culture on the reliability of gas turbine power plant operation, to evaluate the loss of revenue due to high rate of intervention (or failure) in the power plant. Materials were collected from the manufacturers manual, maintenance report $\log$ sheet, production report $\log$ book/sheets, intervention schedule programmes, mechanical vibration analyzer machines, machine lubrication schedule/plan, Instrumentation calibration manuals and plants simulation model log books/sheets, human machine interface system (HMI) as well as the equipment control and monitoring machine (ECM), self-administered questionnaire and internet system. The collated data were analyzed with the aid of number of intervention, mean time between failures (MTBF), mean time to repair (MTTR), production yield, loss of revenue equations as well as responses from returned questionnaires to determine the effect of adequate maintenance of the power plant on productivity. The analysis revealed a negative growth rate in productivity resulting from poor performance of the gas turbine power plant in the year (2013-2017) due to poor maintenance culture. There has been colossal loss of revenue due to incessant shutdown of power plant which also affects the process plants. From the result of five years average yield of Notore historical products cost per day for two major products namely; ammonia and urea amounted to N0.1104B. In other words, for one production year, revenue of N36.4 Billion would have been received but due to high plant down-time for maintenance intervention, the company lost about No.851Billion in a year. This is a huge loss to Notore Chemical Industries Plc.
\end{abstract}

Index Terms-Effective Maintenance, Productivity, Power Plant, Intervention, Revenue.

\section{INTRODUCTION}

In the new age of industrialization and even in everyday life, electrical energy is regarded as the most required form of energy. It is to this end, that the standard of living in any country is measured by the availability of electrical energy and its per capita consumption. Presently, the growth in the economy of a country is largely dependent on the availability of electrical energy as it is required in sectors of agriculture, production, manufacturing, processing, and even in transportation. In the middle of the eighteenth through twentieth century, the industrial world strived and prospered. This was however limited to the absence of robust power generation system.

Published on April 8, 2019.

Authors are with the Department of Mechanical Engineering, Rivers State University, Port Harcourt, Nigeria. (e-mail: daniel.humphrey1@gmail.com)
The gas turbine is a complex stationary machine used for the efficient generation of electric power to run industrial equipment to meet production needs. They are usually standalone units or in conjunction with steam power plants either as cogeneration or combined cycle gas turbine where the exhaust gas serves as a heat source for steam generation. The problem faced by the energy engineer will be to generate large quantities of electrical energy at low cost, and maintain a steady supply to the consumers, with minimal impact on the environment. Nearly in every sector today, there is a high drive towards the use of gas turbine because of its comparative advantages over the internal combustion engines.

An effective maintenance of the gas turbine power plant is therefore important in order to supply electricity with high reliability level to the production/process plant in a safe manner and at reduced cost. This result in improved reliability, greater profitability, and higher productivity as downtime is reduced in the main production process. This further implies that when power generating plant is consistently improved by correct maintenance procedures, the process plants or production system will be very effective using Notore chemical industries Plc as a case study [1]. The main objective of maintenance engineering is to provide freedom from breakdown during manufacturing operations.

According to [2] maintenance of equipment and machinery in any firm is a nuisance demanding enormous resources of manpower and materials. However, it is absolutely essential if plant, machinery and equipment are to remain in acceptable condition and ready for use when they are required. The decision is never whether maintenance should take place, but the form it should take to make it economically effective.

[2] and [3] in their papers on maintenance management or small-scale industries reported that apart from the above objective, maintenance of equipment is also essential in order to:

1. Maintain the equipment at their maximum operating efficiencies

2. Maintain equipment in a satisfactory condition for safe operations

3. Reduce to a minimum, the cost of this maintenance consistent with the above items.

[4] appraised the gas turbine power plant maintenance system in Nigeria. He revealed that electric power projects in many countries, except Nigeria, are reliable. Failures in electric power plants result in downtime, production losses and economic losses as well. Obviously, to achieve the global maintenance objective of realizing high machinery availability at minimum cost, adequate cognizance must be 
given to the element that makes up the cost of machine unavailability and the cost of maintenance resources.

[5] carried out a research on managing power plant and utilities in $\mathrm{R} \& \mathrm{P}$ subsidiaries of NNPC refinery and petrochemical power plant. Thus, described Power Plant and Utilities as complexes saddled with the responsibilities of providing safe, reliable and secured electric power, steam, water (cooling, drinking, utility and boiler feed), air (instrument, plant), and nitrogen for the continuous operation of the process plants and other facilities in our refineries and petrochemical plants. $\mathrm{He}$ stated these in a paper titled 'Managing Power Plant and Utilities in NNPC Refining and Petrochemical Subsidiaries' at the 4th R and P Technical Seminar. He went on to say that 'For some time now, the Power Plant and Utilities facilities have been weakened in the smooth and sustained operation of the Process Plants which have no other sources of power and utilities due to unreliability of supply from the public utility companies.' He blamed the situation amongst others, to poor maintenance culture and called for effective maintenance of our equipment to reverse the situation.

There is hardly a duration of three months' interval that the power plant will not be shut down due to one failure or the other. Invariably, the process plants which by design capacity should produce three hundred thousand metric tons (300,000MT) of Ammonia, and five hundred thousand metric tons $(500,000 \mathrm{MT})$ of Urea fertilizer in a year respectively is never achieved. Trucks queue for a long period of time before fertilizers are delivered to farmers. Importation of fertilizers as well as the price is on the increase.

In Notore Chemical Industries Plc, most shut down of process plants or production systems are usually associated to;

i. Breakdown of equipment and machinery in the power generating plant due to instrument failures

ii. Poor monitoring and maintenance of the gas turbine and generators

iii. Unavailability of spare parts

iv. Low gas supply and treatment at the conditioning skid.

v. Regular postponement of turnaround maintenance (TAM).

A good operational policy is necessary for the maintenance department to discharge its responsibilities and realize the objectives for which it was established. A company can adopt any form of maintenance policy which suits it. From the works of [6], [2] and [7] the various forms of maintenance policy are: -

In this policy, the equipment is operated until it breaks down and then it is scrapped and a new one is bought. The maintenance engineer may discover that the cost of repair exceeds the cost of replacement for small, easily replaceable and cheap equipment. Sometimes, technological advancement causes some equipment to become obsolete rapidly; hence, it does not pay to design to last. When they fail, they are out of date so may as well be replaced.

In this policy the equipment is operated and then sold before it either breaks down, or requires expensive overhaul. This system is often applied in many branches of industry especially in those in which the equipment operates as an individual unit - small power plant, machine tools, mobile cranes, mobile generators and motor vehicles. Some important advantages of this system is that it reduces downtime caused by breakdowns and prevents costly overhauls while restricting maintenance function to lubrication, servicing, cleaning and adjustment only. Car fleets are normally operated on the basis of planned replacement. Also, many private motorists run their own vehicles on this basis.

In this policy, the equipment operates until it breaks down and is then repaired. In a situation where the cost of preventing failure of plant or equipment are more than the cost of breakdown, it is often justifiable financially to allow the machine to break down before carrying out any maintenance. This system is usually applied where many items of plant and equipment operate as individual units, or are separated from the actual manufacturing process, so their failure would not immediately or greatly affect the overall production process or constitute a safety hazard. For example, a man operating a tailoring workshop may find that it is easier, cheaper and quicker, with less loss of production, to allow the sewing machines to break down and then replaces them with repaired ones held in stock for such occurrence.

Preventive maintenance is the anticipation of failures and the adoption of necessary preventive actions before they occur. The main objective of preventive maintenance is to effect the work of inspection, servicing and adjustment and so prevent the failure of equipment during operation [2] (Akubuo 1991). The benefits of preventive maintenance are:

1. Regular, simple preventive maintenance results in less downtime than infrequent expensive and emergency maintenance.

2. Maintenance is carried out when it is most convenient to both production and maintenance personnel with the aim of incurring minimal losses.

3. The volume of maintenance work is distributed evenly throughout the year thus reducing widely fluctuating demands upon the maintenance personnel.

4. There will be greater plant availability because of fewer breakdowns.

5. Regular preventive maintenance ensures a high level of plant output, quality performance and efficiency [8] (Agunwamba 1995),

6. Downtime is reduced considerably since equipment/spares needed are known and are made available in advance.

7. Also, effective control over weekly work allocation is enhanced since weekly work load is known.

8. Through a well-coordinated preventive maintenance programme, life expectancy of parts and materials can be determined. Equipment and machine depreciation rate can be reduced with a good preventive maintenance application.

9. Functioning of machine parts can be determined with the aid of measuring devices employed in preventive maintenance activities. This will help in establishing more accurate replacement periods.

Corrective maintenance is the form of maintenance carried out to restore (including adjustment and repair) an item which has ceased to meet an acceptable condition. 
Corrective maintenance relies on obtaining information of all breakdowns, their causes and the costs incurred as a result of downtime. With this information, usually referred to as plant history, efforts are then made to eliminate such breakdown by:

1. Re-scheduling the maintenance services

2. Re-designing or improving the equipment

3. Changing the process and

4. Altering operating instructions.

Emergency repair maintenance is that type of work carried out after a facility which no advance thought has been given has failed. Emergency repair maintenance is an undesirable occurrence. In fact, [9] Lockyer (1982) is of the view that effectiveness of any maintenance department should not. be judged by the rigour with which emergency repairs are carried out but by the freedom of the factory from such emergencies. Also [10] Hodson (1967) is of the view that a good maintenance programme should reduce the number and intensity of emergency repairs to the point where no more than 15 percent of the total maintenance effort is devoted to emergency work. Usually emergency breakdown has a serious consequence, especially, to life and property. This kind of maintenance usually disrupts production activities leading to downtime.

Overhaul maintenance refers to the servicing of a machine by dismantling the various parts. Usually, the machine will not have developed any fault before this type of maintenance is carried out.

In this policy, the plant or equipment, for instance, a whole refinery, is shut down at a specified time interval determined by the company's policy and serious maintenance work are carried out.

Running maintenance is the type of maintenance carried out while the machine is in operation. Usually, the component to be repaired is not in rotary motion.

In adopting a maintenance policy one over-riding factor is cost. A relationship exists between preventive, corrective and indirect maintenance costs, which is non-linear. When little or no preventive maintenance is being done, there is a high degree of corrective maintenance and subsiquent1y, high corrective and indirect maintenance costs. A small degree of preventive maintenance brings a far more than commensurate benefit. However, there is a limit for which no amount of preventive maintenance will ever eliminate breakdowns entirely. Therefore, there is a point at which the total cost, sum of preventive, corrective and indirect maintenance will be at its lowest and this is the optimum level of preventive maintenance. Any effort on preventive maintenance more than this becomes uneconomical, [2] Akubuo, 1991; [11] Banga et al., 1992)

Predictive maintenance is more feasible today because of technology that is available for equipment surveillance and diagnosis of problems while the machines are still operating. The condition of a machine can be monitored by several means. Sensors may be installed, or periodic readings may be taken with portable units to measure vibration or temperature. Vibration sensors and ultrasonic sensors are used to feed data in to a computer for analysis. The deviation from the normal vibration pattern recorded when the machine is running properly are analyzed to determine where the problem is developing and when it will become serious. A problem of this type prevents unplanned downtime that disrupts production schedules. The objectives of condition-based maintenance are;

i. To detect the failures before they occur.

ii. To carry out maintenance only when required.

iii. To reduce the maintenance costs and downtime costs.

The management of maintenance depends not only upon such technical aspects as the nature, extent and timing of work, but equally critically upon the proper planning and control of resources, especially finances. Maintenance demands an enormous amount of resources, in terms of finance, manpower and materials, but, failure to maintain demands, even more of these resources. Maintenance is absolutely necessary if machinery, plant, equipment and buildings are to remain in acceptable condition, functioning reliably and ready for use when needed. Because of the enormous resources which are involved in maintenance (about $20-30 \%$ of running cost of most factories), there is always need to budget for maintenance. Cost control in maintenance is simply keeping maintenance costs within the budgeted limits. Thus, in maintenance, we always aim at minimum costs and maximum quality bearing in mind the price to be charged for the products [2] (Koboa-Aduama, 1991). The total cost of running a maintenance programme is the sum of indirect maintenance costs and direct maintenance costs. Indirect costs are costs associated with losses of production through breakdowns, extra cost of production through badly maintained plant and defective output caused by lack of maintenance. Preventive and unplanned maintenance costs constitute direct costs that is, cost of labour, materials and equipment for maintenance.

Apart from finance which have just been discussed, other resources of maintenance as presented by [7] Offiong (1992) are maintenance workshop, maintenance personnels, maintenance tools and maintenance spare parts/materials.

Maintenance workshop - For the task of maintenance to be carried out in a comfortable way, workshop must be set up for performing maintenance tasks. A small industrial company might have just one central workshop where all its maintenance tasks that cannot be accomplished on the worksite are taken to. A large company might have different types of workshops for different kinds of maintenance jobs. For example, they might have instrument, electrical, mechanical and refrigeration /air conditioning workshops.

Maintenance personnel - Ineffective personnel organization structure for maintenance has been identified as one of the reasons for lack of maintenance culture in Nigeria [12] (Nwachukwu, 1994). The structure of maintenance personnel organization depends largely on the size of the company. In a small company, some of the maintenance function can be performed by production personnel's and it is not important to differentiate between maintenance function and production function. In a large company, the two functions will be differentiated because of the volume of work involved. Here, instead of placing maintenance tasks under production control, maintenance tasks are directed by maintenance personnel. Also, in a large company, it is often necessary to place the maintenance department on the same/almost the same level of 
organization as production department.

\section{MATERIALS AND METHODS}

\section{A. Materials}

In carrying out this research work information and technical data about the experimental machine (gas turbine) is collated from the following sources:

i. Maintenance report log books

ii. Production report log books/sheet

iii. Intervention schedule programmes

iv. Mechanical vibration analyzer machines

v. Machine lubrication schedule/plan

vi. Instrumentation calibration manuals and plant simulation model log books/sheets

vii. Human machine interface system (HMI) as well as the equipment control and monitoring machine (ECM).

viii. Self-administered questionnaire.

\section{B. Methods}

The approach used in this study is analytical. Thus achieving the aim and objectives, the following procedures were carried out.

i. It involved the use of formal and informal interviews, such as personal interviews, questionnaire administered to the work force and use of available and relevant records.

ii. This research work analyses the gas turbine power plant behavior with respect to its measured mechanical vibration trend analysis, power generation over a period of time, plant availability in terms of running hours.

iii. Application of probability method in estimation of loss of revenue in the entire plant production processes, resulting from the high intervention as well as comparison of manufacturer's recommended MTBF and its operating MTBF condition.

\section{Analytical Approach}

The anomalies in the current maintenance system of the Notore gas turbine power plant as a setback on the productivity of the process plant is analyzed in terms of its mechanical vibration trends, power output generation over a period of time, plant availability in terms of its running hours, loss of revenue resulting from the high rate of interventions and its operating MTBF conditions as itemized below:

a. Mechanical vibration analysis: Data were collected from the measurement of mechanical vibration levels from the maintenance records of the gas turbine power plant as shown in Tables I and II.

b. Power output generation/running hours over 5 years period. A record of yearly and running hour production data is collected and shown in Table III.

c. Intervention cost and loss of revenue: When the process plant fails or it is shut down as a result of gas turbine failure in power plant, lots of hours of production time is lost in repairing the turbine. At least a minimum of 24 hours of production time is lost in the repairs. Taking the gas turbine power plant off production line through maintenance work repair plan and bringing it back after repairs to the plant for installation, cost a lost of money. These expenses and loses are evaluated using:

i. Intervention (failure) could be evaluated by:

$$
\mathrm{N}(\mathrm{t})=\lambda t^{\beta}
$$

where

$\mathrm{N}=$ Number of intervention

$\mathrm{t}=$ Time interval

$\lambda=$ failure rate

$\beta=$ slope

Mean Time between Failure (MTBF), which is defined as the average time

between successive failures, could be estimated from:

$$
\mathrm{MTBF}=\frac{\text { Total time }(\text { hrs })}{\text { Total intervention }}
$$

Mean Time to Repair (MTTR): This is the average time required to troubleshoot and repair failed equipment and return it to normal operating conditions.

Production cost per day (P.C.P.D): This is a product of percentage yield (\%y), daily production (D.P) and cost per unit product (C.U.P).

That is:

$$
\text { P.C.P.D = \% } \mathrm{Y} \text { x D.P x C.U.P }
$$

Revenue Loss: Total revenue loss due to down time of the process plants is given as a function of the probability of failure (P.F) and total cost of product.

That is

Revenue loss $=$ P.F $x$ total cost of daily production

Thus;

$$
\mathrm{P} . \mathrm{F}=\left(\frac{M T T R}{M T T R+M T B F}\right) S . F
$$

where

P.F = Probability of failure

MTTR = Mean time to repair

$\mathrm{SF}=$ Safety factor

MTBF $=$ Mean time between failure

\section{RESULTS AND DISCUSSION}

\section{A. Trend Analysis}

Using the data collected from the gas turbine power plant and utilities, maintenance and production as shown in Table I to Table $\mathrm{V}$ together with the equations in section 2 , then the gas turbine power plant behavior in respect of its mechanical vibration level, power output, plant availability and percentage

product yield is shown in Fig. 1 to 5. Also, loss of revenue from intervention and operating MTBF condition are analyzed.

Table I. Mechanical Vibration level on 2006 GTGO1DE (Vertical Direction)

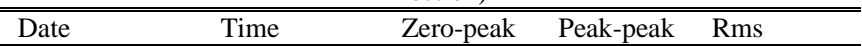




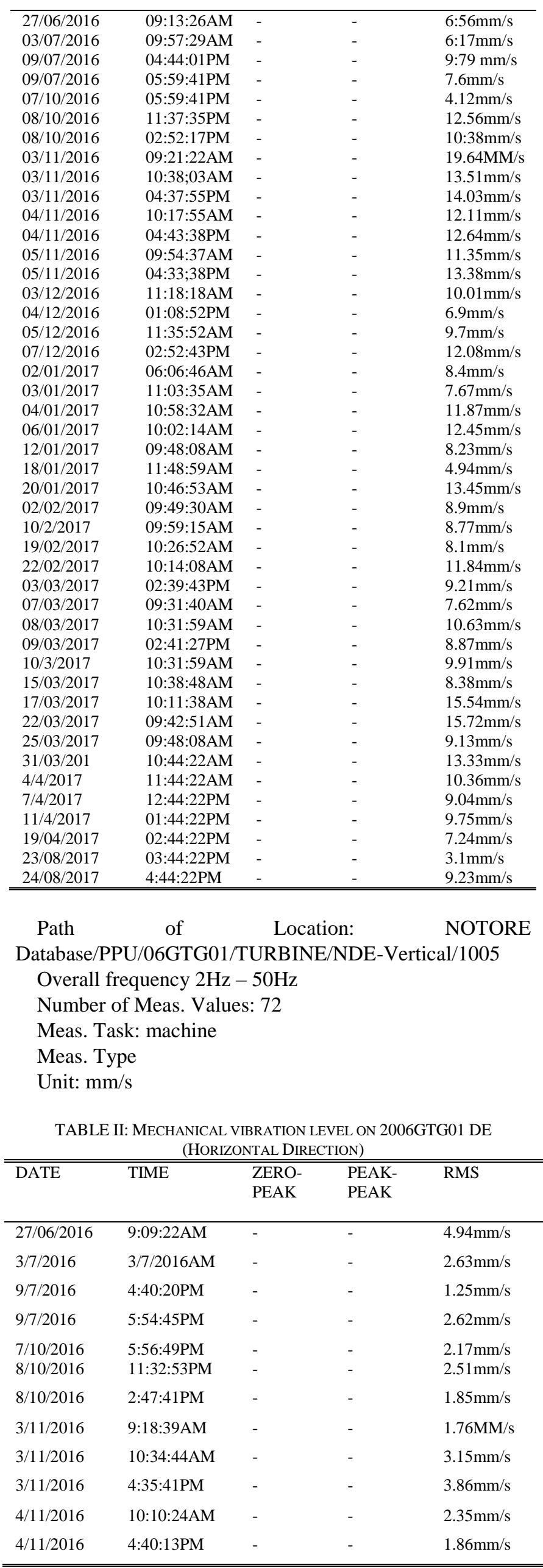

\begin{tabular}{|c|c|c|c|c|}
\hline 5/11/2016 & 9:52:11AM & - & - & $1.86 \mathrm{~mm} / \mathrm{s}$ \\
\hline $5 / 11 / 2016$ & $4: 31: 23 \mathrm{PM}$ & - & - & $2.15 \mathrm{~mm} / \mathrm{s}$ \\
\hline $3 / 12 / 2016$ & $11: 16: 35 \mathrm{AM}$ & - & - & $1.2 \mathrm{~mm} / \mathrm{s}$ \\
\hline $4 / 12 / 2016$ & 1:06:28PM & - & - & $1.18 \mathrm{~mm} / \mathrm{s}$ \\
\hline $5 / 12 / 2016$ & 11:33:08AM & - & - & $1.1 \mathrm{~mm} / \mathrm{s}$ \\
\hline $7 / 12 / 2016$ & $2: 50: 46 \mathrm{PM}$ & - & - & $1.47 \mathrm{~mm} / \mathrm{s}$ \\
\hline $2 / 1 / 2017$ & $6: 04: 28 \mathrm{AM}$ & - & - & $2.49 \mathrm{~mm} / \mathrm{s}$ \\
\hline $3 / 1 / 2017$ & 10:59:11AM & - & - & $9.38 \mathrm{~mm} / \mathrm{s}$ \\
\hline 4/1/2017 & 10:55:57AM & - & - & $2.72 \mathrm{~mm} / \mathrm{s}$ \\
\hline $6 / 1 / 2017$ & $10: 00: 25 \mathrm{AM}$ & - & - & $3.6 \mathrm{~mm} / \mathrm{s}$ \\
\hline $12 / 1 / 2017$ & 09:46:32AM & - & - & $6.66 \mathrm{~mm} / \mathrm{s}$ \\
\hline $18 / 01 / 2017$ & $11: 47: 01 \mathrm{AM}$ & - & - & $2.64 \mathrm{~mm} / \mathrm{s}$ \\
\hline $20 / 01 / 2017$ & $10: 45: 08 \mathrm{AM}$ & - & - & $6.79 \mathrm{~mm} / \mathrm{s}$ \\
\hline $2 / 2 / 2017$ & 09:47:52AM & - & - & $7.57 \mathrm{~mm} / \mathrm{s}$ \\
\hline $10 / 2 / 2017$ & 09:57:53AM & - & - & $6.56 \mathrm{~mm} / \mathrm{s}$ \\
\hline $19 / 02 / 2017$ & $10: 25: 30 \mathrm{AM}$ & - & - & $1.87 \mathrm{~mm} / \mathrm{s}$ \\
\hline $22 / 02 / 2017$ & 10:12:29AM & - & - & $2.06 \mathrm{~mm} / \mathrm{s}$ \\
\hline $3 / 3 / 2017$ & 02:38:07PM & - & - & $2.65 \mathrm{~mm} / \mathrm{s}$ \\
\hline 7/3/2017 & 09:30:14AM & - & - & $8.9 \mathrm{~mm} / \mathrm{s}$ \\
\hline $8 / 3 / 2017$ & 10:52:03AM & - & - & $12.01 \mathrm{~mm} / \mathrm{s}$ \\
\hline $9 / 3 / 2017$ & 02:38:02PM & - & - & $3.35 \mathrm{~mm} / \mathrm{s}$ \\
\hline $10 / 3 / 2017$ & 10:30:43AM & - & - & $4.07 \mathrm{~mm} / \mathrm{s}$ \\
\hline $15 / 03 / 2017$ & $10: 37: 43 \mathrm{AM}$ & - & - & $3.21 \mathrm{~mm} / \mathrm{s}$ \\
\hline $17 / 03 / 2017$ & 10:10:14AM & - & - & $11.19 \mathrm{~mm} / \mathrm{s}$ \\
\hline $22 / 03 / 2017$ & 09:41:30AM & - & - & $10.97 \mathrm{~mm} / \mathrm{s}$ \\
\hline $25 / 03 / 2017$ & $11: 25: 25 \mathrm{AM}$ & - & - & $6.91 \mathrm{~mm} / \mathrm{s}$ \\
\hline $31 / 03 / 201$ & 10:42:44AM & - & - & $7.62 \mathrm{~mm} / \mathrm{s}$ \\
\hline 4/4/2017 & 10:37:10AM & - & - & $3 \mathrm{~mm} / \mathrm{s}$ \\
\hline $7 / 4 / 2017$ & 10:46:48AM & - & - & $4.35 \mathrm{~mm} / \mathrm{s}$ \\
\hline $11 / 4 / 2017$ & $09: 28: 25 \mathrm{AM}$ & - & - & $3.93 \mathrm{~mm} / \mathrm{s}$ \\
\hline $19 / 04 / 2017$ & 10:01:31AM & - & - & $3.47 \mathrm{~mm} / \mathrm{s}$ \\
\hline $23 / 08 / 2017$ & 06:33:59PM & 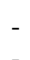 & - & $1.95 \mathrm{~mm} / \mathrm{s}$ \\
\hline
\end{tabular}

Path of Location: NOTORE

Database/PPU/06GTG01/TURBINE/NDE-Horizontal/1005

Overall frequency $2 \mathrm{~Hz}-50 \mathrm{~Hz} 2$

Number of Meas. Values: 72

Meas. Task; Machine

Meas. Type

Unit: $\mathrm{mm} /$

TABLE III: SUMMARY OF POWER GENERATION, RUNNING HOURS OF GTG IN NOTORE 2013-2017

\begin{tabular}{lllll}
\hline \hline Year & $\begin{array}{l}\text { GTG01 } \\
\text { Power } \\
(\mathrm{MW})\end{array}$ & $\begin{array}{l}\text { Running Hours } \\
\text { (HRS) }\end{array}$ & $\begin{array}{l}\text { GTG02 } \\
\text { Power } \\
\text { (MW) }\end{array}$ & $\begin{array}{l}\text { Running Hours } \\
\text { (HRS) }\end{array}$ \\
\hline 2013 & 52406.6 & 6048.0 & - & - \\
2014 & 65684.0 & 8520.0 & - & - \\
2015 & 70798.7 & 8327.0 & - & - \\
2016 & 32680.0 & 4271.8 & - & - \\
2017 & 20953.0 & 2794.9 & - & - \\
TOTAL & 242522.3 & 29961.7 & 0 & 0 \\
\hline \hline
\end{tabular}

For ease of clarification the information as collated above 
are shown and analyzed with the aid of micro excel graphic plots, statistical bar charts and pie charts presentations as in Fig. 1 to 5 respectively.

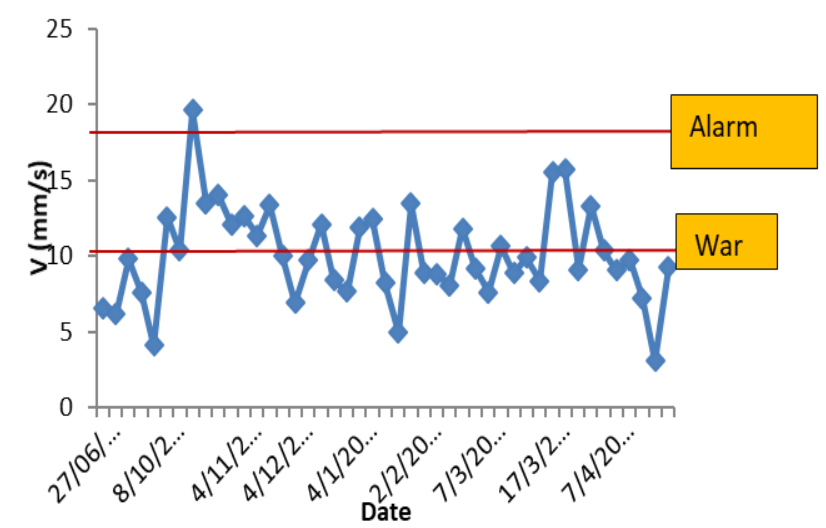

Fig. 1. Mechanical vibration Level Trends on 2006GTG01 DE (Vertical Direction.

The above is the trend vibration levels on the turbine 06GTG01 DE (vertical direction) from 27/06/2016 to 24/08/2017. The levels in the month of November 2016 were above alarm level. Remedial actions taken in the month of April 2017 reduced the levels below warning level. The Equipment is still in use pending the time spare parts will be available to carry out corrective action.

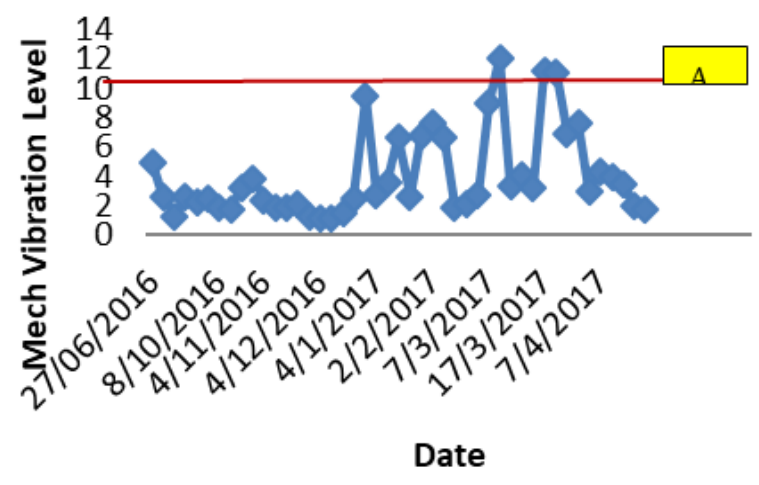

Fig. 2. Mechanical Vibration Level Trend on 06GTG01 NDE (Horizontal Direction.

The above is the trend of overall vibration levels on the turbine 06GTG01 NDE (horizontal direction) from $27 / 06 / 2016$ to $24 / 08 / 2017$. The levels in the months of February to March 2017 were above warning level. Further analysis revealed journal-bearing failure. Corrective action taken by the month of April brought the level to within acceptable limits.

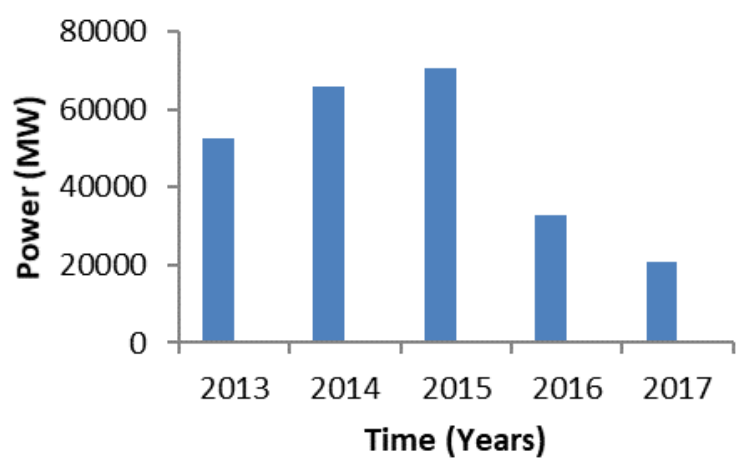

Fig. 3. Power Generation in Notore.

Fig. 3 indicates that power in year 2013 to 2015 was on the increase with little shut down for maintenance of the turbo generator (GTG01). Whereas, year 2016 to 2017 had decrease of power generation owing to frequent shut down for maintenance.

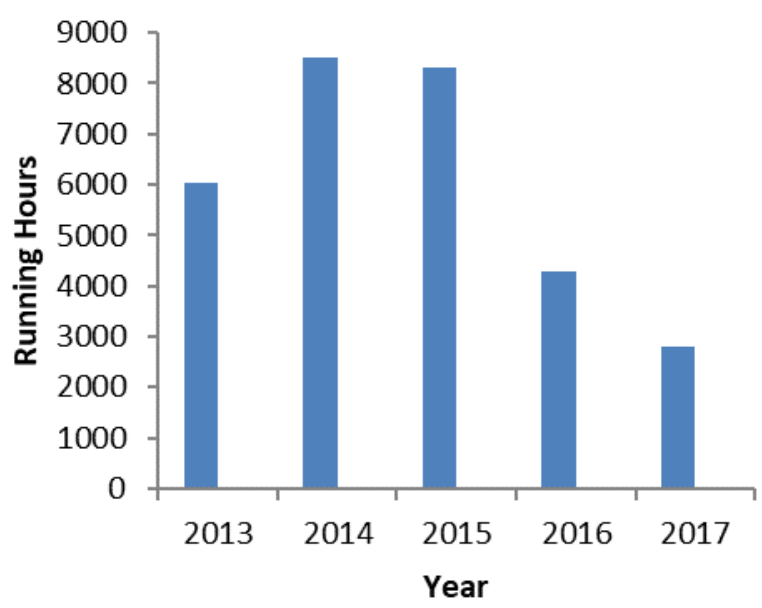

Fig. 4. Running Hours of GTGs.

Fig. 4 above indicates that the gas turbine generators performed better and longer operational hours in year 2013 to 2015 but from 2016 to 2017 , there was poor performance of the gas turbine generators resulting in epileptic power supply from the power plant. This goes to confirm frequent downtime of gas turbines in 2016 to date because of poor maintenance of which an effective maintenance is sought.

TABLE IV: PERCENTAGe Yield of MAJOR PRODUCTS IN NOTORE FOR YEAR 2013 TO 2017

\begin{tabular}{lllll}
\hline \hline \multicolumn{2}{l}{ Yields in \% WT } & & & \\
Year & Ammonia & Urea & Others & Total \\
\hline 2013 & 36.32 & 47.80 & 15.88 & 100 \\
2014 & 39.42 & 49.42 & 11.16 & 100 \\
2015 & 43.38 & 49.62 & 7.00 & 100 \\
2016 & 39.54 & 47.78 & 12.68 & 100 \\
2017 & 34.29 & 38.60 & 27.11 & 100 \\
Average & & & & 100 \\
$(2013-2017)$ & 38.59 & 46.64 & 14.74 & \\
\end{tabular}




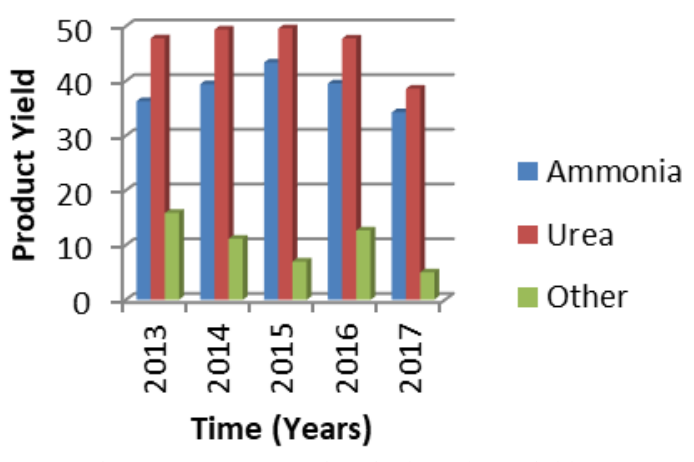

Fig. 5. NOTORE'S Historical Product Yields.

The above clearly shows a negative growth in reliability, because from Fig. 5 it is clearly noted that between the year 2013 to 2015 there was a corresponding increase in yield for Ammonia and urea production, indicating good maintenance practice in those years. Immediately after 2015 , the trend of percentage yield drops rapidly between 2016 and 2017 as a result of poor maintenance.

\section{B. Average Cost Per Intervention}

When the process plant fails or it is shutdown as a result of gas turbine failure in power plant, lots of hours of production time is lost in repairing of the turbine. At least a minimum of 24 hours of production time is lost in the repairs. Taking the turbine off production line to maintenance work-repair plan and bringing it back after repairs to the plant for installation, cost a lot of money. The money expended is summarized as follows:

TABLE V: SHOWS THE AVERAGE COST OF AN INTERVENTION IN THE GAS TURBINE POWER PLANT OPERATION. (SOURCE: NOTORE PROCUREMENT DEPARTMENT)

\begin{tabular}{|c|c|c|}
\hline $\mathrm{S} / \mathrm{N}$ & Activities & Amount (N) \\
\hline 1. & Logistics & $200,000.00$ \\
\hline 2. & Incidents for bearing replacement & $400,000.00$ \\
\hline 3. & Incidents for labyrinth seal replacement & $200,000.00$ \\
\hline 4. & 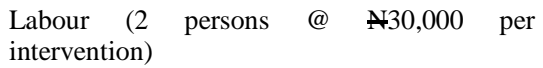 & $60,000.00$ \\
\hline 5. & Miscellaneous & $200,000.00$ \\
\hline 6. & Total & $1,060,000.00$ \\
\hline
\end{tabular}

\section{SUMMARY OF CALCULATED COST}

INTERVENTION, MEAN TIME BETWEEN FAILURE, PRODUCT COST PER DAY, LOSS OF REVENUE

C.

a. Cost Intervention

Number of intervention is given by;

$\mathrm{N}(\mathrm{t})=\lambda \mathrm{t}^{\wedge} \beta$

Where;

$\mathrm{N}=$ no. of intervention, $\lambda=$ failure rate

$\beta=$ Slope, $\mathrm{t}=$ time interval

For, $\mathrm{t}=5$ years $=43800$ hrs (i.e. $5 \times 24$ × 365 days).

And, $\lambda=0.0038511$ (at $97 \%$ confidence), $\beta=0.840$

$\Rightarrow \mathrm{N}(\mathrm{t})=0.0038511 \times 438000.840$

$=0.0038511 \times 792206=31$ interventions in 5 years $=$ $31 / 5$ per year $=6.2$ interventions per year.

Using N1,060,000.00 as average cost of an intervention in the gas turbine power plant (See Table 9), it means that; Notore has spent $(6.2$ intervention) $\mathrm{x}(\mathrm{N} 1,06,000.00)$ in a year $=\mathrm{N} 6,572,000.00$ on turbine related intervention alone. b. Mean Time Between Failure (MTBF)

$\mathrm{MTBF}=($ Total time $(\mathrm{hrs})) /($ Total interventions $)=(8760$ $\mathrm{hrs}) / 6.2=1,412.9 \mathrm{hrs}$ per years

c. Product cost per day (PCPD)

$\mathrm{PCPD}=\%$ yield $\mathrm{x}$ daily production $\mathrm{x}$ cost per unit of product

For Ammonia product (NH3)

$\%$ yield $=38.59 \%$, daily production at $90 \%=900 \mathrm{MT}$, cost per MT $=\mathrm{N} 64,000.00$

$\Rightarrow$ PCPD $(\mathrm{NH} 3)=(38.59) / 100 \times 900 \times 6400$

$=\mathrm{N} 22,227,840.00$

Urea Product

$\%$ yield $=46.64 \%$, daily production at $90 \%=1350 \mathrm{MT}$

Cost per MT $=$ N140,000

$\Rightarrow$ PCDP $($ Urea $)=46.64 / 100 \times 1350 \times 140,000$

$=\mathrm{N} 88,149,600.00$

Thus; cost per day for Ammonia and Urea Product $=\mathrm{N} 22,227,840+\mathrm{N} 88,149,600$

$=\mathrm{N} 110,377,400.00$ (Total cost of daily production)

d. Loss of Revenue (RL):

$\mathrm{RL}=\mathrm{P} . \mathrm{F} \mathrm{x}$ total cost of daily production

But;

P.F $=$ MTTR/(MTTR+MTBF $) \times$ SF

Where;

P. F = Probability of failure, MTTR $=24 \mathrm{hrs}$ (assumed),

$\mathrm{S} . \mathrm{F}=1.4, \mathrm{MTBF}=1,412.9 \mathrm{hrs}$.

$\Rightarrow$ P.F $=24 \mathrm{hrs} /(24 \mathrm{hrs}+1,412.9 \mathrm{hrs}) \times 1.4=33.6 / 1436.9$

$\therefore \mathrm{P} . \mathrm{F}=0.02338$

Hence, Revenue loss due to downtime (failure) of the process plant is

$0.02338 \times \mathrm{N} 36.4 \mathrm{~B}=\mathrm{N} 0.851 \mathrm{~B}$ per year

\section{CONCLUSION}

This research work has been able to determine the effectiveness of a good maintenance culture on the reliability of Notore gas turbine Power plant operation via the analysis of the mechanical vibration levels (vertical and horizontal directions), power output generation, power plant availability, loss of production and loss of revenue due to high rate of intervention (failure).

From the result it is observed that in the past five years, Notore power plant has a record of very high unreliability with capacity utilization of less than $60 \%$ and on-stream availability less than $65 \%$. This is consistent with the result of reliability gotten from the calculation, which shows a significant degradation.

When turbine fails and trips or carefully shut-down, it takes at least 24 hours to bring it back on-stream, on the basis of taking the turbine off production line to maintenance workshop or worksite. And of course, labour, logistics and other cost considerations shows that very huge amount of money has been expended for the maintenance interventions within the short period of time. This clearly shows a negative growth rate in productivity resulting from poor performance of the gas turbine power plant in those years (2013-2017) under review. Thus there has been colossal loss of revenue due to incessant shutdown of power 
plant that directly affects the process plants. From the result of five years average yield of Notore historical products cost per day for two major products namely; ammonia and urea amounted to N0.1104B. In other words, for one production year, revenue of $\mathrm{N} 36.4$ Billion would have been received but due to high plant down-time for maintenance intervention, the company lost about N0.851Billion in a year. This is a huge loss to Notore Chemical Industries Plc.

Individual reactions on the responses from the study questions of years of poor maintenance of the power plant and utilities further explained that a significant degradation of power plant utilities (PPU), came up in 2013-2017.

The following are some of the reasons for frequent breakdown of gas turbine power plant and utilities in Notore Chemical Industries Plc:

i. Poor turn-around Maintenance (TAM) execution; this is found to be often postponed the moment the plant could manage to run.

ii. Inadequate equipment monitoring. Equipment are not adequately monitored as required to check for changes in vibration, temperature, noise, etc, in order to predict faults and rectify them before equipment breakdown. This is also attributed to faulty annunciations thereby making certain parameters to be ran above alarm points.

iii. Lack of Spare parts: Inadequate stock servicing spare parts is a major constraint affecting the achievement of an effective and efficient maintenance.

iv. Poor funding of operation and maintenance activities

v. Poor motivation of the workers.

vi. Lack of adequate tools and equipment are major constraint to maintenance of the plant.

This study has demonstrated that effective maintenance of gas turbine power plant is quite necessary to improve productivity in our agro-allied, petrochemical, oil and gas industries. It is clearly observed that achieving high plant availability and reliability, will save the company substantial cost from the cost of maintenance interventions.

\section{ACKNOWLEDGMENT}

Individuals and organizations contributed in no small measure to the successful completion of this project work. The immeasurable assistance is hereby acknowledged.

We would like to thank the management and staff of Notore Chemical Industries Plc, particularly the departments of power plant and utilities, maintenance, and production for the privilege given to us to use their facilities to carry out this study. We remain indepted to Mr. Henry Teeyor, Mr. Fabian Dike - manager urea plant, Mr. Maxin Alfred - urea plant superintendent and Engr. Mrs. Osaigbovo Onwuchekwa - supervisor, technical service department for finding deep interest in the work, and for several pieces of information and advice.

Finally, special thanks to Imerami vine, Gbonee Barikuura, Benneth Anumihe, and a host of others for their numerous technical support especially Eric Rokalima for the assistance in typing the work. May God richly bless you all.

\section{REFERENCES}

[1] Peterson, J. R. (1977). Heavy-Duty Gas Turbine Maintenance Practices, General Electric (GE) Gas Turbine Reference Library.

[2] Koboa-Aduama, B. (1991), Maintenance management of small scale industries, in the proceedings of the international conference/working on engineering for accelerated rural development.

[3] Onwuazo, C. J. (1989). Design and simulation of a group management scheme for small scale industries in an urban area Master's Thesis, Department of Mechanical Engineering, University of Nigeria, Nsukka.

[4] Oyedopo S. O. (2013). Appraisal of the Gas Turbine Power plant maintenance system in Nigeria.

[5] Ahmed, M. (2001). Managing power plant and utilities in R \& P subsidiaries, 4th NNPC refinery and petrochemical technical seminar, Port Harcourt.

[6] Schroeder, W. J. (1989)), Planned maintenance in maintenance engineering resources pack (Unpublished)

[7] Offiong, A. (1992). Design of a computer based maintenance management system for industries. The case study of Ferdinand Oil Mill Plc. Urualla, Imo State, Master's Thesis, Department of Mechanical Engineering, University of Nigeria, Nsukka.

[8] Agunwamba, J. C. (1995). Effect of maintenance on waste stabilization pod performance. Journal of Agriculture and Technology, 4, 1.

[9] Lockyer, K. G. (1982). Factory and production management, London, 118-126 and 333- 342 .

[10] Hodson, W. (1967). Control of maintenance costs, in standard handbooks for mechanical engineers (7th ed.) McGraw, New York, 17-47.

[11] Banga, T. R., Agarwal, N. K. and Sharma, S. C. (1992), Industrial Engineering and management science (7th ed), Khana Publishers, Delhi, 662.

[12] Nwachukwu. J.C. (1994) "Condition Monitoring Techniques need not be very sophisticated and expensive", in proceedings of the first National Conference of Nigeria Constituting Production Engineers, University of Benin, Benin City 87 - 94. J. U. Duncombe, "Infrared navigation-Part I: An assessment of feasibility," IEEE Trans. Electron Devices, vol. ED-11, pp. 34-39, Jan. 1959. 